\title{
Knowledge and home management of diarrhoeal disease among mothers with under-five children attending university of Uyo teaching hospital, Nigeria
}

\author{
Akpan MU', Ijezie $\mathbf{E}^{2}$ \\ ${ }^{1}$ Dr. Mkpouto Udeme Akpan, ${ }^{2}$ Dr. Echey Ijezie, both authors are affiliated with Department of Paediatrics, University of \\ Uyo Teaching Hospital, P.M.B., Uyo, Akwa Ibom State, Nigeria
}

Correspondence Author: Dr. Mkpouto Udeme Akpan, Department of Paediatrics, University of Uyo Teaching Hospital, P.M.B. Uyo, Akwa Ibom State, Nigeria. Email: mkpoutoakpan@yahoo.com

\begin{abstract}
Background: Diarrhoea is a major cause of mortality in under-five children worldwide, but more especially in developing countries including Nigeria. Most of the deaths are due to dehydration and its mismanagement at home. Mothers' good knowledge and proper home management will help reduce its morbidity and mortality rates. Aim: To assess the knowledge of diarrhoea and home management among mothers with under-five children attending the University of Uyo Teaching Hospital, Uyo, Nigeria. Methods: A twenty-two item structured questionnaire was administered to 370 mothers with at least one under-five child who attended either the Children's Emergency Unit or the Paediatric clinic of the University of Uyo Teaching Hospital. The questionnaire bordered on knowledge, prevention, home management and attitudes of mothers toward diarrhoea. Results: Majority (86.2\%) of the women knew that drinking dirty water can cause diarrhoea, 175 (47.3\%) believed teething causes diarrhoea, 177 (47.8\%) knew that human faeces could be a source of diarrhoea, while $332(89.7 \%)$ knew that hand-washing prevents one from developing diarrhoea. Their level of knowledge of signs of dehydration was low with $45.7 \%, 62.4 \%, 27.8 \%$ and $42.2 \%$ identifying sunken eyes, thirst and dry mouth, tearless eyes and loss of stretchiness of the skin as signs of dehydration respectively. Conclusion: Though mothers had good knowledge of causes, and home management of diarrhoea, there are still knowledge gaps. Efforts to bridge the gaps should be tackled through periodic and regular health education programs for the mothers
\end{abstract}

Key words: knowledge, home management, diarrhoea, under-five, Uyo.

\section{Introduction}

Diarrhoea is defined as the passage of three or more loose stools in twenty-four hours [1]. It is a preventable and treatable disease, and second to pneumonia as the leading cause of under-five mortality globally [2]. Diarrhoea is responsible for 1.9 million deaths among children less than five years of age, especially in developing countries [3]. Diarrhoea has been ranked as the fourth leading cause of mortality among under-five children in Nigeria [4]. Preventable infectious diseases such as malaria, pneumonia, diarrhoea, measles and Human Immunodeficiency Virus/ Acquired Immune Deficiency Syndrome (HIV/AIDS) account for more than $70 \%$ of estimated one million under-five deaths in Nigeria [5].

Manuscript received: $6^{\text {th }}$ April 2018

Reviewed: $16^{\text {th }}$ April 2018

Author Corrected: $24^{\text {th }}$ April 2018

Accepted for Publication: $28^{\text {th }}$ April 2018
Most cases of diarrhoea results from infection in the intestinal tract. Several organisms are responsible for the infection. They include viruses, bacteria and parasites. The child gets infected through contaminated foods and drinking water, and from person to person due to poor hygiene [6]. Lack of safe water, basic sanitation and hygiene may account for $88 \%$ of diarrhoeal disease [7].

Diarrhoeal episodes may last for several days and the major cause of death is severe dehydration with electrolyte imbalance. In many developing countries including Nigeria, most diarrhoeal episodes are treated at home and mothers are the key caregivers to underfive children [8]. Therefore, their knowledge of diarrhoea as well as actions to prevent and manage the disease will help to reduce the morbidity and mortality 
associated with diarrhoea [9]. Abiola et al in their study in Sokoto, North-Western Nigeria, reported a good knowledge of diarrhoea disease among mothers [10]. No such study known to the authors has been reported in our environment. This study therefore sought to assess the knowledge and home treatment of diarrhoea among mothers of under-five children presenting in a tertiary health facility in Uyo, Nigeria.

\section{Materials and Method}

Study Area: This study was conducted in Children's Out-Patient (CHOP) and Children's Emergency Unit (CHEU), both of the Paediatrics Department of the University of Uyo Teaching Hospital (UUTH), Uyo in Nigeria.The Teaching Hospital is located six kilometres from the heart of the metropolis and serves as a referral centre to patients within and outside the state.

The Children's Out-Patient Clinic is run on a daily basis, alongside different Paediatric subspecialty clinics. All children below the age of eighteen years who present to UUTH, not as emergencies and within the official hours are seen in the CHOP Clinic. There is a full complement of health staff to cater for the sick children who present in the CHOP clinic. They include trained Paediatric nurses, House-officers, Resident Doctors and Consultant Paediatricians who run the subspecialty clinics. A laboratory unit and pharmacy unit are attached to the clinic. Mothers usually receive health education on some common childhood illnesses such as diarrhoea, management of fever and febrile convulsion at home at the beginning of each day's activities.

The Children's Emergency Unit has a twenty-two bed capacity and attends to emergency clinical conditions from the age of six weeks to eighteen years. It has an isolation room and a diarrhoea treatment room attached to it. Patients admitted in CHEU are treated and monitored for twenty-four to forty eight hours to stabilise after which they are either discharged home or transferred to the Paediatric ward. The CHEU has a Consultant Paediatrician as a supervisor with other staff such as resident doctors, house officers and nurses working under him. A paediatric nurse is attached to the diarrhoea treatment room and takes care of children on admission for diarrhoea and its complications. The nurse is also responsible for educating the mothers on causes, prevent and home treatment of diarrhoea.

Study design and study period: This descriptive and prospective study was conducted over a two month period from $1^{\text {st }}$ February, 2018 to $31^{\text {st }}$ March, 2018.
Ethical approval: Written assent was obtained from the mothers and their participation was voluntary. It was emphasized to every mother that she is free to withdraw from the study at any stage she is no longer comfortable.

Ethical clearance to carry out the study was obtained from the Ethical committee of the University of Uyo Teaching Hospital, Uyo.

\section{Minimum sample size:}

Sample size was calculated using the formula:

$$
\begin{gathered}
n=z^{2}(p)(1-p) \\
d^{2}
\end{gathered}
$$

where $\mathrm{n}=$ minimum sample size

$\mathrm{z}=$ the standard score corresponding to a given confidence level (1.96)

$\mathrm{p}=$ mothers' knowledge of diarrhoeal disease in Sokoto in North-western Nigeria which is $59.7 \%$ [10].

$\mathrm{d}=$ tolerable error $(0.05)$

Minimum sample size using the above formula is 370 .

\section{Inclusion criteria}

1. Mothers with at least one child that is under the age of five years.

2. Mothers who have given written assent to participate in the study.

\section{Exclusion criteria}

1. Mothers without children under the age of five years.

2. Mothers who did not give their consent to participate in the study.

Instrument and method: The instrument for the study is a twenty-two item structured questionnaire and this was administered on the recruited mothers. The questionnaire bordered on age, marital status, religion, knowledge and home management of diarrhoea. A pilot study was conducted to pre-test the instrument among twenty mothers in the Paediatric Clinic, and these mothers were excluded from the final sample for the study. The investigators were available to assist in filling the questionnaire. Mothers were consecutively recruited until the minimum sample size was achieved.

Statistical Method: Data obtained was analyzed using SPSS 20 package. Frequencies were obtained using frequency tables and compared using Chi-square; $p$ value of $<0.05$ was regarded as significant. 


\section{Results}

A total of three hundred and seventy mothers took part in the study. Majority $(50.3 \%)$ of the mothers were in the $30-39$ years age group, $29.7 \%$ in the $20-29$ years age group, $14.3 \%$ were $40-49$ years old while $3.8 \%$ and $1.9 \%$ were $<20$ years old and $\geq 50$ years old respectively. Three hundred and twenty-six $(88.1 \%)$ mothers were married and $9.5 \%$ were widowed. Two hundred and six (55.7\%) of the mothers had tertiary education, with majority (98\%) of the mothers practising Christianity. The demographic characteristics of the study population are as shown in table 1.

Table-1: Demographic characteristics of the mothers.

\begin{tabular}{|c|c|}
\hline & N (\%) \\
\hline \multicolumn{2}{|l|}{ Age(years) } \\
\hline$<20$ years & $14(3.8)$ \\
\hline $20-29$ & $110(29.7)$ \\
\hline $30-39$ & $186(50.3)$ \\
\hline $40-49$ & $53(14.3)$ \\
\hline 50 and more & $7(1.9)$ \\
\hline \multicolumn{2}{|l|}{ Marital status } \\
\hline Married & $326(88.1)$ \\
\hline Single & $35(9.5)$ \\
\hline Widowed & $5(1.4)$ \\
\hline Separated & $4(1.1)$ \\
\hline \multicolumn{2}{|l|}{ Educational level } \\
\hline No formal education & $4(1.1)$ \\
\hline Primary & $30(8.1)$ \\
\hline Secondary & $130(35.1)$ \\
\hline Tertiary & $206(55.7)$ \\
\hline \multicolumn{2}{|l|}{ Religion } \\
\hline Christianity & $364(98.4)$ \\
\hline Moslem & $02(0.5)$ \\
\hline Traditional & $04(1.1)$ \\
\hline Total & $370(100)$ \\
\hline
\end{tabular}

Mothers' knowledge of diarrhoea and its danger signs: Table 2 shows the knowledge of mothers of the causes and mode of transmission of diarrhoea. Majority of the mothers know that drinking dirty water, eating dirty foods as well as eating with dirty hands can cause diarrhoea $(86.2 \%, 75.7 \%$ and $81.4 \%$ respectively).

Though $234(63.2 \%)$ mothers knew that flies can transmit the causative agent of diarrhoea, majority did not know that defaecating in the open field and eating soil can lead to having diarrhoea (61.6\% and $71.4 \%$ respectively).

Most (64.3\%) mothers knew that the passage of three or more loose stools with blood is a danger sign in a child with diarrhoea.

Other danger signs such as sunken eyes, tearless eyes and loss of stretchiness of the skin were not known by the mothers as danger signs; however, $62.4 \%$ of them knew that thirst with dry mouth in a child with diarrhoea signified danger. The knowledge of mothers about causes and mode of transmission of diarrhoea are shown in table 3. 
Table-2: knowledge of causes/mode transmission of diarrhoea by mothers

\begin{tabular}{|c|c|c|}
\hline & True & False \\
\hline & N (\%) $(\%)$ \\
\hline Drinking dirty water causes diarrhoea & $319(86.2)$ & $51(13.8)$ \\
\hline Eating dirty food can cause diarrhoea & $280(75.7)$ & $90(24.3)$ \\
\hline Eating with dirty hands can cause diarrhoea & $301(81.4)$ & $69(18.6)$ \\
\hline Eating with dirty utensils causes diarrhoea & $270(73.0)$ & $100(27.0)$ \\
\hline Flies cause diarrhoea & $234(63.2)$ & $136(36.8)$ \\
\hline Defaecating in open field can lead to diarrhoea & $142(38.4)$ & $228(61.6)$ \\
\hline Eating soil can cause diarrhoea & $106(28.6)$ & $264(71.4)$ \\
\hline
\end{tabular}

Table 3: Recognition of danger signs of diarrhoea by the mothers

\begin{tabular}{|c|c|c|}
\hline & True & False \\
\hline Three or more loose stool with blood within 24hours & N (\%) \\
\hline Thirst and dry mouth & $238(64.3)$ & $132(35.7)$ \\
\hline Sunken eyes & $231(62.4)$ & $139(37.6)$ \\
\hline Tearless eyes & $169(45.7)$ & $201(54.3)$ \\
\hline Loss of stretchiness of skin & $103(27.8)$ & $267(72.2)$ \\
\hline
\end{tabular}

Knowledge of methods of prevention and home management of diarrhoea by the mothers: Regarding mothers' knowledge of methods of prevention of diarrhoeal disease, $84.6 \%$ knew that drinking clean water can prevent diarrhoea, $25.7 \%$ knew that using toilet for defaecation prevents diarrhoea, while $70.8 \%$ and $44.1 \%$ knew that storing water in clean container and treating water with chemical prevent diarrhoea respectively. This is shown in table 4.

Mothers' knowledge of home treatment of diarrhoea was good, though $234(65.7 \%)$ of them felt seeking medical treatment is the first thing that should be done when a child comes down with diarrhoea.

Three hundred and twenty-seven (88.4\%) knew that oral rehydration salt solution should be commenced at home immediately a child develops diarrhoea. Also, 207 (55.9\%) and 360 (97.3\%) mothers knew that a child with diarrhoea should continue breastfeeding for those that are still breast feeding and food should not be stopped for those not breastfeeding respectively.

However, majority $(74.6 \%)$ of the mothers did not know that home-made fluids should be given to a child during diarrhoeal episodes.

Table-4: knowledge of prevention of diarrhoea by the mothers

\begin{tabular}{|c|c|c|}
\hline & True & False \\
\hline & N (\%) & N (\%) \\
\hline Drinking clean water & $313(84.6)$ & $57(15.4)$ \\
\hline Handling food unhygienically & $61(16.5)$ & $309(83.5)$ \\
\hline Using toilet for defaecation & $95(25.7)$ & $275(74.3)$ \\
\hline Storing water in clean container & $262(70.8)$ & $108(29.2)$ \\
\hline Treating water with chemical & $163(44.1)$ & $207(55.9)$ \\
\hline
\end{tabular}


Table-5: Home management of diarrhoea by the mothers

\begin{tabular}{|c|c|c|}
\hline & True & False \\
\hline Seek modern treatment & $\mathbf{N}(\%)$ & N(\%) \\
\hline Give oral rehydration solution & $243(65.7)$ & $43(11.6)$ \\
\hline Continue breastfeeding & $327(88.4)$ & $163(44.1)$ \\
\hline Give home-made fluids & $207(55.9)$ & $276(74.6)$ \\
\hline Stop feeding & $94(25.4)$ & $360(97.3)$ \\
\hline
\end{tabular}

Table-6: Attitude of mothers toward diarrhoeal disease

\begin{tabular}{|c|c|c|c|}
\hline & True & False & Don't know \\
\hline & N (\%) & N (\%) & N (\%) \\
\hline Diarrhoea attacks mainly bottle-fed children & $171(46.2)$ & $123(33.3)$ & $76(20.5)$ \\
\hline Diarrhoea is a disease of the poor & $30(8.1)$ & $307(80.0)$ & $33(8.9)$ \\
\hline Diarrhoea is a killer disease & $304(82.2)$ & $23(6.2)$ & $43(11.6)$ \\
\hline Diarrhoea is a curable disease & $318(86.0)$ & $12(3.2)$ & $40(10.8)$ \\
\hline Teething causes diarrhoea & $175(47.3)$ & $194(28.1)$ & $91(24.6)$ \\
\hline It is important to breastfeed during diarrhoea & $274(74.1)$ & $19(5.1)$ & $77(20.8)$ \\
\hline Human faeces is a source of diarrhoea & $177(47.8)$ & $84(22.7)$ & $109(29.5)$ \\
\hline Hand-washing prevents diarrhoea & $332(89.7)$ & $07(1.9)$ & $31(8.4)$ \\
\hline
\end{tabular}

Regarding mothers' attitude toward diarrhoea, majority of mothers (53.8\%) did not know that diarrhoea attacks mostly bottle-fed children but $304(82.2 \%)$ knew that it is a killer disease. Three hundred and eighteen $(86.0 \%)$ respondents knew that diarrhoea is a curable disease while 175 (47.3\%) believed that teething causes diarrhoea. Majority (89.7\%) of the mothers were aware that hand-washing prevents diarrhoea and 52.2\% did not know that human faeces is a source of diarrhoea. This is shown in table 6.

\section{Discussion}

Childhood diarrhoea is a common public health concern and it is a wide spread problem in developing countries, Nigeria inclusive. It is a common cause of morbidity and mortality in children under the age of five years. It is therefore necessary to assess the knowledge and home management of diarrhoea among mothers with under-five children so as to plan organised health education for them.

Though mothers were aware of the causes and mode of transmission of diarrhoea in this study, the level of awareness was insufficient in certain aspects. Mothers' knowledge level regarding the cause and transmission of diarrhoea by drinking dirty water was found to be very high $(86.2 \%)$. This was higher than findings from Malawi and Kenya in which the knowledge level was $55 \%$ and $58.2 \%$ respectively $[9,11]$. A study conducted in Ethiopia reported a knowledge level as low as $20.15 \%$ [12]. This disparity could be attributed to the difference in educational background of the mothers in the different studies. In this study as well as in the Malawian study,majority ( $98.9 \%$ and $79 \%$ respectively) of the women had elementary education and above while in Ethiopian study, only $25 \%$ of the women attended school up to elementary level and above. Knowledge of mothers on danger signs in this study was low. Though majority of the mothers knew that passage of three or more loose stool in 24 hours is an immediate danger sign, knowledge of signs of dehydration was poor. The finding that majority of the mothers had knowledge that passage of three or more loose stools with blood is a danger sign was also reported in a study done in a rural community of Kenya in which $76.4 \%$ of their respondents against $64.3 \%$ in this study mentioned the appropriate answer [9].

This was contrary to the findings in Ethiopia in which $39.5 \%$ of their respondents knew the correct answer [12]. This could be attributed to the difference in the educational background of the women in the different studies. Forty-four point five percent of the mothers identified signs of dehydration. This is also similar to findings among mothers in a Sudanese rural community [13]. The observation that $65.7 \%$ of mothers in the 
present study would seek modern medical treatment such as taking the child to the hospital was similar to what was reported in Ethiopia (62.2\%) and Kenya [9, 13]. It is worthy of note that, some mothers $(3.0 \%)$ preferred taking their children with diarrhoea to traditional healers for treatment. This practice should be discouraged as it may predispose the child to increase mortality and morbidity.

Three hundred and twenty-seven (88.4\%) mothers in the present study advocate the use of oral rehydration solution for treatment of diarrhoea which compares well with the report that $73.1 \%$ of mothers in a study in Enugu offered oral rehydration solution to their children with diarrhoea [14]. This is contrary to the observation made by Ahmed et al in which the rate of use of oral rehydration solution was as low as $24.4 \%$ and $8.4 \%$ respectively in past and current episode of diarrhoea [15]. Also, a study in Enugu, Nigeria reported a low knowledge on the of oral rehydration solution about fifteen years after the introduction of oral rehydration therapy into Nigeria by UNICEF [16]. Another study in North-Western reported oral rehydration use to be abysmally low at $8.6 \%$ [17].

The reason for the low level of knowledge in their study might have been as a result of a drop in the level of education and awareness of mothers on diarrhoeal management due to poor public enlightenment on the topic. World Health Organisation (WHO) advocates the use of ORS and it is easily available even in remotest part of our environment. The observation that $2.7 \%$ of women studied advocated withholding feeds whenever a child develops diarrhoea was also reported in India as well as in other parts of Nigeria and Kenya [15, 18, 19].

The reason for withholding feeds during diarrhoea may be due to cultural beliefs. The finding that $25.4 \%$ of mothers knew that home-made fluids could be used during diarrhoea is higher than the $9.5 \%$ which was reported in Ethiopia [20]. The possible reason for the difference could be that they were more knowledgeable considering the fact that daily health education program takes place in the children's outpatient before commencement of consultations. It could also be due to the fact that majority of our mothers have elementary education and above as studies both within and outside Nigeria had shown that this category of mothers have good knowledge of diarrhoea and its management [17, 20, 21]. Mothers' association of diarrhoea with teething in this study may impact on their health seeking behaviour. A similar observation was reported in a study in Kenya and Port Harcourt, Nigeria in which
$73.9 \%$ and $47.5 \%$ respective mothers associated diarrhoea with teething in their children [22, 23]. More health education programmes should be carried out as diarrhoea is a killer disease that needs prompt attention.

\section{Conclusion}

This study adds to the existing knowledge of diarrhoea by demonstrating that though mothers had good knowledge of causes, and home management of diarrhoea, there are still knowledge gaps.The knowledge of mothers is essential for reduction of frequency of occurrence of diarrhoea among the underfive children. Early identification and management of diarrhoea at home is essential in preventing death from dehydration. Efforts to bridge the gaps should be tackled through periodic and regular health education programs for the mothers.

Authors Contribution- MUA conceived and designed the study, wrote the introduction, methodology and discussion. EI analyzed the data, wrote the results. Both Authors approved the final version for publication.

Funding: Nil, Conflict of interest: None initiated, Perission from IRB: Yes

\section{References}

1. Amare D, Dereje B, Kassie B, Tessema M, Mullu G, Alene B, et al. Maternal knowledge and practice towards diarrhoea management in under five children in Fenote Selam town, West Gojjam zone, Amhara regional state, Northwest Ethiopia. J Infect Dis Ther. 2014; 2: 182. Doi: 10.4172/2332-0877.1000182.

2. UNICEF. Pneumonia and diarrhoea tackling the deadliest diseases of the world's poorest children. New York, NY: UNICEF; 2012.

3. Boschi-Pinto C, Velebit L, Shibuya K. Estimating child mortality due to diarrhoea in developing countries. Bul World Health Organ. 2008; 86: 710-17.

4. WHO, author. Reducing mortality from major childhood killer diseases . Mortality Country Fact Sheet. 2006. https//apps.who.int/chd/publications/ imci/ fc_ $180 . \mathrm{htm}$.

5. UNICEF Nigeria, author. The child - Maternal and child health. http:// www.unicef.org/nigeria/ children 1926.html.

6. World Health Organization. Diarrhoeal disease fact sheet. 2013; No.330. 
7. Environmental Health Project, author. Lesson Learnt (Oct.2002). PNA-CY112. www.ehproject.org.

8. Ghasemi AA, Talebian A, Masoudi Alavin N, Mousavi GA. K knowledge of mothers in management of diarrhoea in under five children, in Kashon, Iran. Nurs Midwifery Stud. 2013; 1: 158-62.

9. Othero DM, Orago AS, Groenewegen T, Kaseje DO, Otengah PA. Home management of diarrhoea among under five in a rural community in Kenya: household perceptions and practices. East Afr J Public Health. 2008; 5: 142-6.

10. Abiola AO, Ndamon AL, Idris $\mathrm{SH}$, Jiya NM, Ibrahim MT. Home management of childhood diarrhoea among mothers in Sokoto, Nigeria. Trop J Health. 2010; 17(1) http://dx.doi.org/10.4314/tjhc.v17: 1.52801.

11. Masangwi SJ, Grimason AM, Morse TD, Kazembe L, Ferguson N, Jabu G. Pattern of maternal knowledge and its implications for diarrhoea control in Southern Malawi: multilevel thresholds of change analysis. Int J Environ Res Public Health. 2012; 9: 955-69.

12. Merga N, Alemayehu T. Knowledge, perception and management skills of mothers with under-five children about diarrhoeal disease in indeginous and resettlement in Assosa District, Western Ethiopia. J Health Popul Nutr. 2015 3; 33(1): 20-30.

13. Ahmed IS, Eltom AR, Karrar ZA, Gibril AR. Knowledge, attitudes and practices of mothers regarding diarrhoea in a Sudanese rural community. East Afr Med J. 1994; 71(11): 716-9.

14. Uchendu UO, Emodi IJ, Ikefuna AN. Pre-hospital management of diarrhoea among caregivers presenting at a tertiary health institution: implications for practice and health education. Afr Health Sci. 2011; 11(1): 41-7.

15. Ahmed F, Farheen A, Ali I, Thakur M, Samina M. Management of diarrhoea in under-fives at home and health facilities in Kashmir. Int J Health Sci (Qassim). 2009; 3 (2): 171-5.
16. Adimora GN, Ikefuna AN, Ilechukwu G. Home management of childhood diarrhoea: Need to intensify campaign. Nig J Clin Pract. 2011; 14(2): 237-41.

17. Ogunrinde OG, Raji T, Owolabi OA, Anigo KM. Knowledge, attitude and practice of home management of childhood diarrhoea among caregivers of under-5 children with diarrhoeal disease in Northwestern Nigeria. J Trop Pediatr. 2012; 58(2): 143-6.

18. Okunribido OO, Brirger WR, Omotade OO, Adeyemo AA. Cultural perceptions of diarrhoea and illness management choices among Yoruba mothers in Oyo state, Nigeria. Int Q Community Health Educ. 1997; 17(3): 309-18

19. Oyoo A, Burstrom B, Forsberg B, Makhulo J. Rapid feedback from household surveys in PHC planning: An example from Kenya. Health Policy Plan. 1991; 6(4): 380-3.

20. Desta BK, Assimamaw NT, Ashenafi TD. Knowledge practice and associated factors of homebased management of diarrhoea among caregivers of children attending under-five clinic in Fagita Lekoma district, Awi zone, Amhara Regional state, Northwest Ethiopia. Nurs Res Pract. 2017; doi.org/10.1155/2017/ 8084548.

21. Gazi E, Chowdhury A, Kumar R, Sarkar AP, Basu SS, Sahar S. 'Can mothers care for acute diarrhoeal disease of their under five children effectively at home? A cross sectional study in slum community in Bankura. J Evidence Based Med and Healthcare. 2015; 2 (36): $5575-84$

22. James RM, Gathece LW,Kemoli AM. Association of fever and diarrhoea with infant teething among mothers attending two health centres in Nairobi. J Kenya Dental Assoc. 2015; 6(2): 265-72.

23. Paul NI, Olanrewaju PF. Mothers' perception of teething in children. The Nig Health J. 2014; 14(1): 21-6.

\section{How to cite this article?}

Akpan MU, Ijezie E. Knowledge and home management of diarrhoeal disease among mothers with under-five children attending university of Uyo teaching hospital, Nigeria. Int J Pediatr Res. 2018;5(4):162-168. doi:10.17511/ijpr.2018.i04.02. 